\title{
Research on Strategies of Logistics Talents Training in Higher Vocational Education under the Background of Intelligent Logistics Jingjing Liu
}

\author{
Business School, Wuhan Polytechnic, Guanshan Road, 463\#, Wuhan, China
}

31909078@qq.com

Keywords: Intelligent Logistics; Higher vocational; Talent training; Strategy

\begin{abstract}
With the in-depth application of information technology in the logistics industry, China's logistics has entered the stage of Intelligent logistics. Intelligent logistics has new development trends and opportunities, which brings higher challenges to the cultivation of logistics talents and puts forward higher requirements. Based on the analysis of the characteristics of intelligent logistics and the upgrading of the demand for logistics talents in high-quality logistics, this paper puts forward the countermeasures for the training of high-level logistics talents under the background of intelligent logistics, so to provide reference for the talent training of logistics related majors in higher vocational college in China.
\end{abstract}

\section{Introduction}

Under the background of the new era, China's logistics industry is undergoing profound changes. The advanced technologies such as big data, cloud computing, Internet of Things, artificial intelligence and the logistics industry are deeply integrated and developed. The intelligence of the logistics industry is constantly strengthening.

The express sorting robot is applied in the distribution centers of many companies such as Jingdong, Tmall Warehouse, and China Post, to sort goods efficiently and accurately, and to automate the e-commerce warehouse. Jingdong's intelligent distribution robots have been on the road, and the heavy-duty unmanned aerial vehicles with a capacity of 1-5 tons have been officially launched, as well as intelligent distribution stations and unmanned warehouses. Automatic Storage \& Retrieval System, automatic sorting of sorting robots, intelligent sorting of computer vision inspection, automatic transportation of transport robots, automatic packaging of packaging robots [1], etc., the application of logistics black technologies, all mark the logistics industry in China, no longer traditional warehouse, freight, manual sorting, riding a tricycle to send express mode, but has begun to enter the intelligent logistics stage characterized by "Internet + logistics" [2].

\section{The Characteristics of Intelligent Logistics}

He Liming, president of China Federation of Logistics and Purchasing, believes that intelligent logistics refers to the Internet, which is widely used in the field of logistics, such as Internet of Things, cloud data, artificial intelligence, big data and other new generation information technology, through the Internet and the logistics industry. Connection and deep integration, to achieve intelligent logistics industry, improve logistics operation efficiency and service level of the new business [3].

The report of the 19th National Congress clearly pointed out that China's economy is in the process of transforming the development mode, optimizing the economic structure, and transforming the growth momentum. Intelligent logistics is becoming an important function of the transformation and upgrading of the logistics industry and the reform of the supply side, opening the development of logistics. The new development situation and opportunities have brought higher challenges to the supply of logistics talents and put forward higher requirements.

The development trends of Intelligent logistics are:

Intelligent transportation: It is the use of big data technology to enable the system to automatically generate optimal transportation routes under the support of information, thereby 
changing the situation of relying on manual scheduling; using transportation information platform to realize transportation optimization within the social scope, and then achieve Intelligent transportation.

Intelligent distribution: It is actually integrating traditional distribution with advanced technology to achieve timely and intelligent distribution. At present, many logistics companies have realized the importance of Intelligent distribution for market competition and have deployed strategic deployments. In May 2017, the rookie network released the future green Intelligent logistics car plan, applying a number of "black technologies" to the end of the city.

Intelligent warehousing: It combined with a new generation of information technology to provide a visualization of supply and demand, speed up material flow, reduce costs, create time value, and achieve intelligent control and management of resources[4].

The development of Intelligent logistics has put forward new requirements, bringing new opportunities and challenges for the education and talent training of logistics majors in higher vocational colleges.

\section{The Upgrade of the Demand for High-Quality Logistics Talents under Intelligent Logistics}

With the development of China's logistics industry, the demand for high-quality logistics skills talented by higher vocational colleges has also been continuously upgraded. In the first 10 years of rapid growth of e-commerce business, e-commerce logistics developed at a high speed, and the business volume increased sharply. "November11" and "June18" brought the prosperity of the logistics industry. With the development of cross-border e-commerce, cross-border logistics traffic has increased rapidly, and the demand for cross-border logistics talent has also increased significantly.

During this period, a large number of high-quality, practical and first-line management e-commerce logistics personnel are required to conduct actual operations and management in the e-commerce distribution center and express delivery industry.

After entering the era of intelligent logistics, the demand for logistics talents will change in the following aspects:

The Demand of Basic Operators Will Drastically Reduce. With a large number of automation, artificial intelligence technology and equipment to replace manual operations, more and more enterprises use automated, intelligent equipment to improve logistics efficiency, the needs of basic staff will drastically reduce.

Jingdong's unmanned warehouse and unmanned intelligent distribution station are $100 \%$ operated by robots in warehousing, packaging, sorting and loading. There is no dispatcher, sorter or packager.

New division of labor and cooperation methods such as crowdsourcing, crowdfunding mode and sharing are gradually being widely applied, and the demand for full-time couriers will also be reduced.

The Demand for Compound Talents Will Increase. The increase of platform-type logistics companies, such as the increase of a number of cargo matching and warehouse-matched Internet platforms in recent years, has realized the online docking of supply and demand information and the real-time sharing of idle resources, effectively reducing the cost of social logistics, the increase of such companies will bring demand for "Logistics + Internet" composite talent.

With the application of the Internet of Things and big data in the logistics industry, the demand for compound talents familiar with logistics and Internet of Things, big data analysis and application has increased.

With the rise of the new retail business model, the integration of "Online and Offline + Modern Logistics" has increased the demand for compound talents who understand logistics, e-commerce, marketing and supply chain management.

The intelligent supply chain has developed rapidly, bringing the demand for intelligent supply chain operations talents. With the rise of supply chain finance, the demand for compound talents who understand logistics, Internet and financial services has also increased rapidly. 
The unmanned aerial vehicle has been put into use, resulting in typical jobs in the field of UAV logistics such as research, production, sales, after-sales, operation, maintenance, and customer service, bringing the demand for compound talents who understand the technology and logistics management.

In general, the upgrading of logistics industry enterprises has brought about the transformation of talents from basic positions to compound talents.

The Comprehensive Requirements of Knowledge, Ability and Quality Are Improved. In the era of intelligent logistics, the logistics talents, not only need to master the basic knowledge and skills of logistics professionals, also need to vigorously expand the knowledge, ability scope and personal comprehensive quality.

(1) Knowledge: They cannot be satisfied with the traditional theoretical knowledge of warehousing and distribution, express delivery, transportation, freight forwarding, etc., but need to expand to e-commerce, big data, Internet of Things, logistics and finance, etc., combined with the current advanced information technology to learn. They need to discard outdated and inapplicable theoretical methods and knowledge, and learn advanced methods and knowledge under the conditions of Internet information technology.

(2) Ability: They cannot be satisfied with outdated backward practical skills, such as manual use of lift trucks, the use of manual balers, traditional order picking methods, etc., focusing on strengthening the following aspects:

The ability to improve operational efficiency through information technology, such as using software to optimize transportation and distribution routes, improve transportation and distribution efficiency, and save costs. Improve picking efficiency with picking path optimization software.

The ability to use the Internet for survey analysis, the ability to use the logistics, supply chain information platform, to apply IOT technology and big data analysis, such as customer demand data analysis, customer classification, precision marketing and so on.

(3) Comprehensive quality: It is necessary to strengthen the ability of innovation, cooperation, big data thinking, collaborative sharing thinking, information technology/Internet application, and adapt to the requirements of smart logistics and innovation and entrepreneurship.

\section{The Strategies of Logistics Management Talents Training in Higher Vocational Education under the Background of Intelligent Logistics}

The curriculum system and course content in the traditional logistics talent training model have not kept up with the rapid development of the logistics industry. The actual teaching has lagged behind the industry practice, and the curriculum system and course content need to be optimized and upgraded.

Key reforms and innovations of the training of logistics management talents in higher vocational education should focus on the following aspects: training mode, teaching content, teaching methods, knowledge learning, scientific research, practical practice, innovation and entrepreneurial guidance, and ability training, etc.

The Talent Training Model Needs to be Upgraded. Higher vocational collages can create four types of platforms to upgrade the talent training model.

Talent plan platform: Through the implementation of Warehousing Supervisor Talent Program, International Freight Forwarding, Logistics Big Data Application, Purchasing and Supply Chain Management Talent Program, to achieve stratified classification training of outstanding students.

Innovative and entrepreneurial platform: support logistics, express delivery, innovation and entrepreneurship, providing guidance for students with entrepreneurial spirit and ideas, and incubating excellent entrepreneurial projects. Strengthen students' practical and innovation ability.

Practical teaching platform: apply distribution center warehousing training, logistics virtual training, VR virtual training, logistics simulation software, improve students' practical operation ability, new technology application ability under the background of intelligent logistics.

Open interactive, integrated teaching and learning platform: using information-based teaching methods, future classroom teaching environment, rich resources of Changfeng network teaching 
platform, interactive means, campus platform, etc., to improve teaching results.

Professional Course System Optimization. Complement and upgrade from the perspective of a comprehensive system science, taking into account traditional general courses, professional courses, elective courses, and practical courses. Add Development courses and upgrade Training courses.

Basic Professional courses include: logistics industry cognition, warehousing and distribution management, distribution center operation management, logistics customer service, logistics and transportation management, logistics economic geography, logistics industry English, etc.

Development courses include: add big data analysis, data mining, Internet of Things and cloud computing, such as "Big Data Theory and Analysis Methods", "The Application of IOT technology in the logistics industry".

Training courses include: logistics virtual training, VR virtual training, logistics simulation software, etc.

\section{Course Content Upgrade.}

(1) Knowledge of intelligent logistics should be added to the basic course. For example, in warehousing management course, knowledge of unmanned warehouses should be added, knowledge of unmanned aerial vehicle distribution should be added into transportation course, and knowledge of robot sorting and intelligent warehouse of e-commerce logistics distribution center should be added in distribution center operation course.

Supply chain management can not only learn traditional supply chain theory, but use big data application to all aspects of supply chain management, improve the accuracy of supply chain intermediate information prediction and analysis, reduce supply chain uncertainty, and improve supply chain efficiency.

For example, traditional inventory theory and inventory control methods are now based on big data inventory forecasting methods.

(2) Add system planning and design courses to the senior grade. For example, warehousing design, logistics park planning, logistics system simulation, etc., lay the foundation for the high-quality improvement of the subsequent career.

(3) Upgrade practice teaching. Practical teaching in the school, using advanced practical teaching equipment, teaching methods, logistics virtual training, VR virtual training, logistics simulation software. Practice teaching outside the school, choose the leading enterprises in the industry with high level of intelligent logistics, Jingdong, Suning, SF Express, Wuhan Zhongbai Group, etc., visit companies that have the advanced intelligent logistics operation mode, and invite the instructors in enterprise or industry to the campus to do lectures, introducing advanced management ideas and methods. Keep up with the development of industry and enterprises.

School-enterprise Deep Integration. Strengthen deep cooperation of school with enterprise of logistics training equipment developers, Internet companies, logistics enterprises and enterprise logistics, realize deep integration of schools and enterprises, deep integration of theory and realization, and practice the training mechanism of multi-dimensional integration of government, industry, colleges and research organization.

\section{Conclusion}

The development of intelligent logistics is changing with each passing day. Relevant technologies and applications have brought about an overall upgrade of the logistics industry and a substantial increase in efficiency. In the era of intelligent logistics, the demand for talents in the industry has also undergone tremendous changes. The logistics management major of higher vocational colleges must keep up with the development of the times and industries, innovate talent training methods, update teaching content and methods, and do a good job of school-enterprise deep integration, In this way, it can cope with the talent demand in the new situation.

\section{References}

[1] Information on http://www.sohu.com/a/238558267_735994 
[2] Li Xiang, He Mei, Xie Feng, Discussion on the training mode of applied logistics talents under the background of intelligent logistics, Logistics Engineering and Management, 2018.3, pp. 130-132.

[3] He Liming's speech at the first China Intelligent Logistics Summit Forum 2016

[4] Huang Chengcheng, Ye Chunsen, Wang Xuexuan, Shi Zhangman, Research on the construction of intelligent supply chain system, Value Engineering, 2018.37(23), pp. 121-123 